\title{
An aversive conditioning unit for ants
}

\author{
CHARLES I. ABRAMSON, DANA M. COLLIER, and HENRY MARCUCELLA \\ Boston University, Boston, Massachusetıs 02215
}

\begin{abstract}
An apparatus is described for studying aversive conditioning in ants. The aversive stimulus is mechanically produced vibration. Responses are recorded automatically by an infrared photocell system.
\end{abstract}

The purpose of this paper is to describe an automated aversive conditioning apparatus primarily designed for ant research in which mechanically produced vibratory stimulation is used as the aversive event. Although several studies have used various aversive events such as electric shock and $\mathrm{X}$ ray, they have met with limited success. Due to the small size of the experimental chamber, it has been difficult to construct electric shock grids or resistive sheets that the animal cannot escape by orienting in a particular direction or by remaining stationary in a shock-free zone (Longo, Holland, \& Bitterman, 1961). Martinsen and Kimeldorf (1972) report that ants escape from a compartment bombarded by $X$ rays only during specific times of the year; at other times, X-ray bombardment fails to maintain escape behavior. We have found mechanically produced vibration to be a useful stimulus. It has the advantage of eliminating hazards associated with electrified grids, such as short circuits from urine.

\section{DESCRIPTION OF APPARATUS}

The apparatus described in this paper allows automatic programming of events and of data, thereby eliminating handling of the subject and experimenter bias during the experimental session. Contingencies can be arranged to accommodate free operant or discrete trial procedures.

The apparatus diagrammed in Figure 1 consists of a vibrator (Radio Shack Model 273-048) mounted between the opposite walls of a clear Plexiglas rectangle constructed of $.635-\mathrm{cm}$ thick Plexiglas. Amplitude of vibration can be adjusted by a Variac. Quantification of amplitude is achieved by setting the Variac at selected voltages and measuring the sinusoidal oscillations (Autrum, 1941).

The Plexiglas rectangle is $5.0 \mathrm{~cm}$ long, $3.9 \mathrm{~cm}$ wide, and $5.0 \mathrm{~cm}$ high. A piece of $20 \mathrm{-g}$ aluminum rests directly on the vibrator and functions as the floor of the apparatus. The dimensions between the edge of the floor and the walls of the rectangle are large enough for the floor to freely vibrate but small enough to prevent the subject's injury or escape.

Because of the small size of the subjects relative to the rectangle, the internal dimensions of the apparatus were made smaller by securing partitions to the ceiling at desired locations. In this case, the partitions form a chamber $1.3 \mathrm{~cm}$ long by $1.3 \mathrm{~cm}$ wide by $.5 \mathrm{~cm}$ high. When the ceiling is lowered, the subject is trapped inside. This chamber can be modified into a runway or shuttlebox by simply adding pieces of Plexiglas until the desired apparatus is obtained. A technical drawing of the apparatus is shown in Figure 2.

Responses are automatically recorded by an infrared photocell system. The circuit is diagramed in Figure 3. The infrared emitter directs light into the cube through a hole in the chamber floor. The emitter is mounted so that its top is flush with the floor. The infrared detector is positioned over the ceiling of the chamber directly above the emitter. The output of the detector is connected to an amplification circuit which allows the operation of relay programming equipment. Parts used in the construction of the circuit are listed in Table 1 .

\section{PRELIMINARY DATA}

Data on the acquisition and extinction of the escape response in four ants of the species Pogonmyrmex californicus (California Harvester ants) are presented in Figure 4. The percentage of time on the safety zone is indicated. The safety zone is a $.280-\mathrm{cm}$ area around the photocell that is roughed with sandpaper. A response
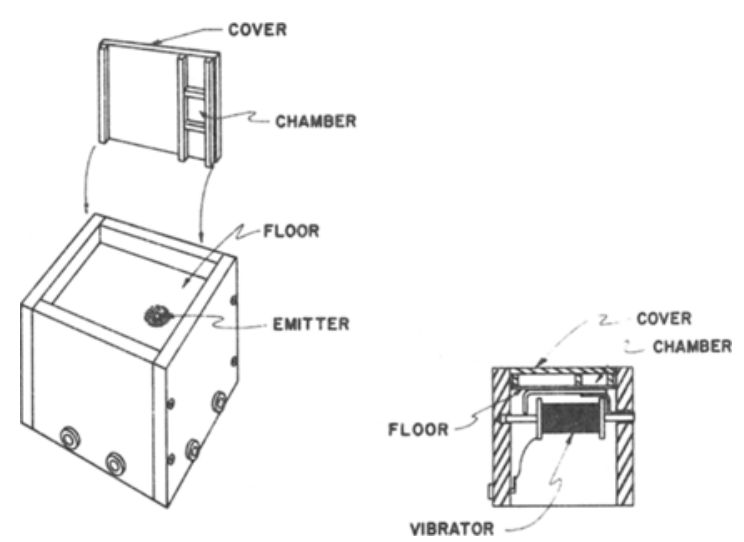

Figure 1. Overview of the apparatus. 


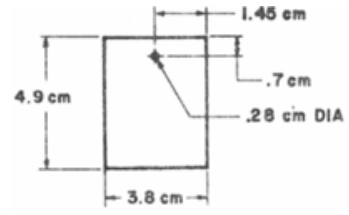

20 GAUGE ALUM.

PLATE

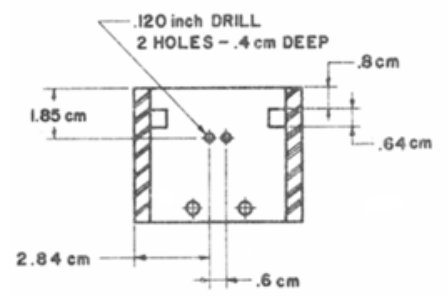

SECTION A-A

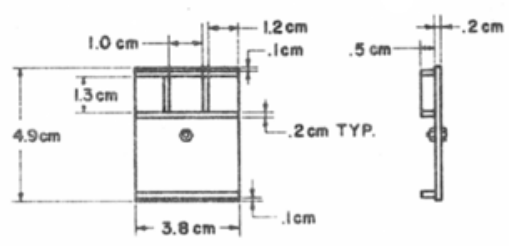

COVER

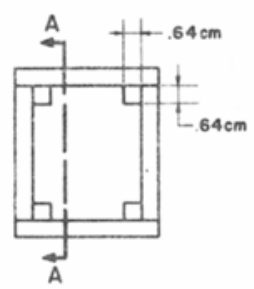

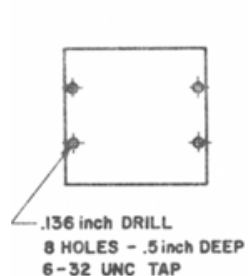
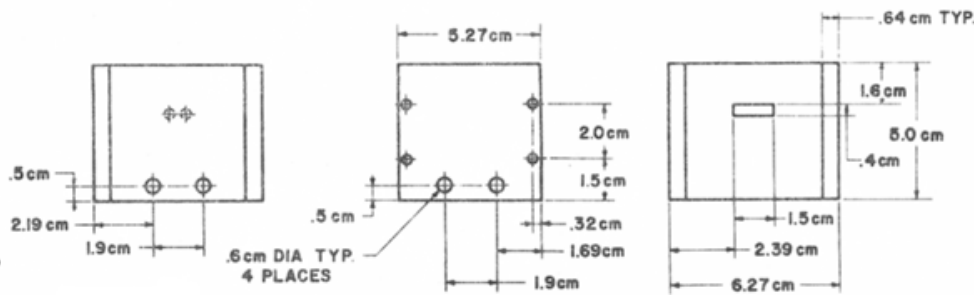

Figure 2. Detailed drawing of the apparatus.

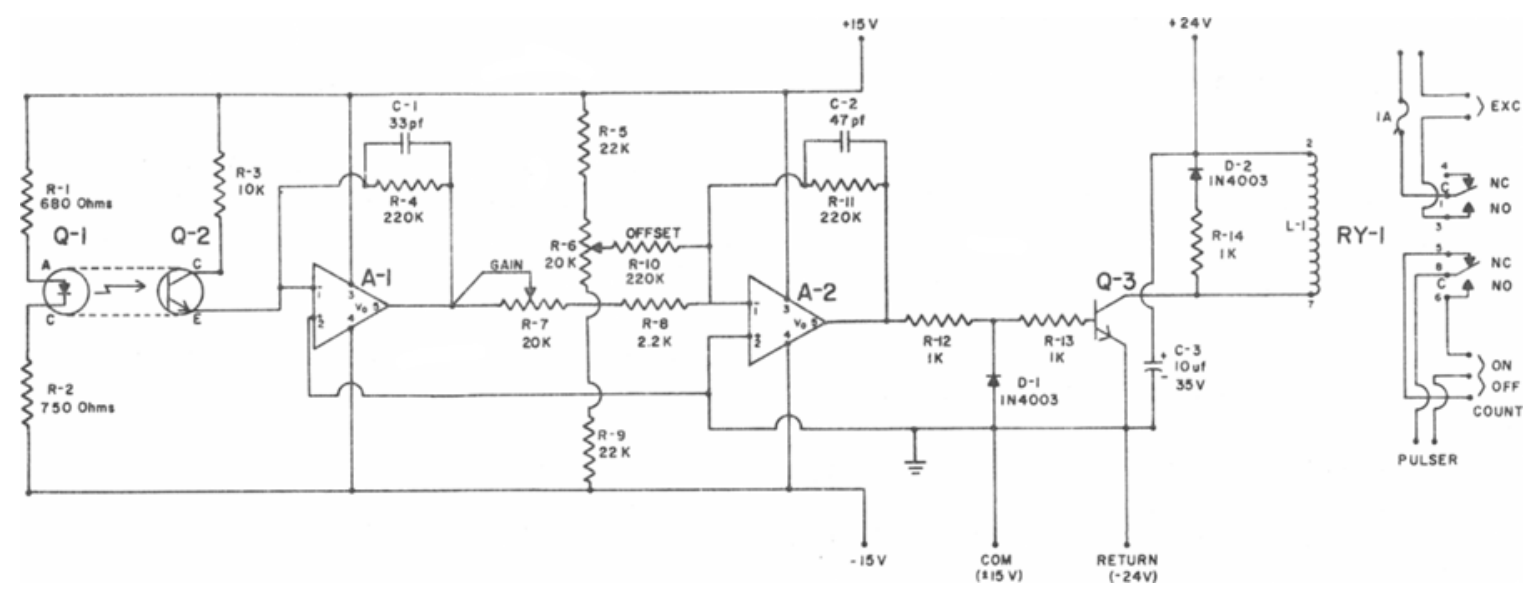

Figure 3. Schematic of amplification system. All resistors are 1/4 W $20 \%$.

Table 1

Parts List

\begin{tabular}{ll}
\hline Q-1 & Light-emitting diode, type TIL-32, Radio Shack \\
Q-2 & Phototransistor, type TIL-63, Radio Shack \\
A-1, A-2 & Operational amplifier, type C-1 18, Bell and Howell \\
Q-3 & Driver transistor, type MPS-U06, Motorola \\
RY-1 & Output relay, type KRP 11-D, Potter-Brumfieid \\
D-1, D-2 & Diode, type IN 4003 \\
\hline
\end{tabular}

occurs when the subject enters this zone and breaks the infrared beam.

Subjects were picked at random from the laboratory colony and placed in individual living compartments where food and water were available ad lib for the duration of the experiment. The Variac was set at $50 \mathrm{~V}$. No attempt was made to quantify the vibration in the manner previously described (Autrum, 1941). 

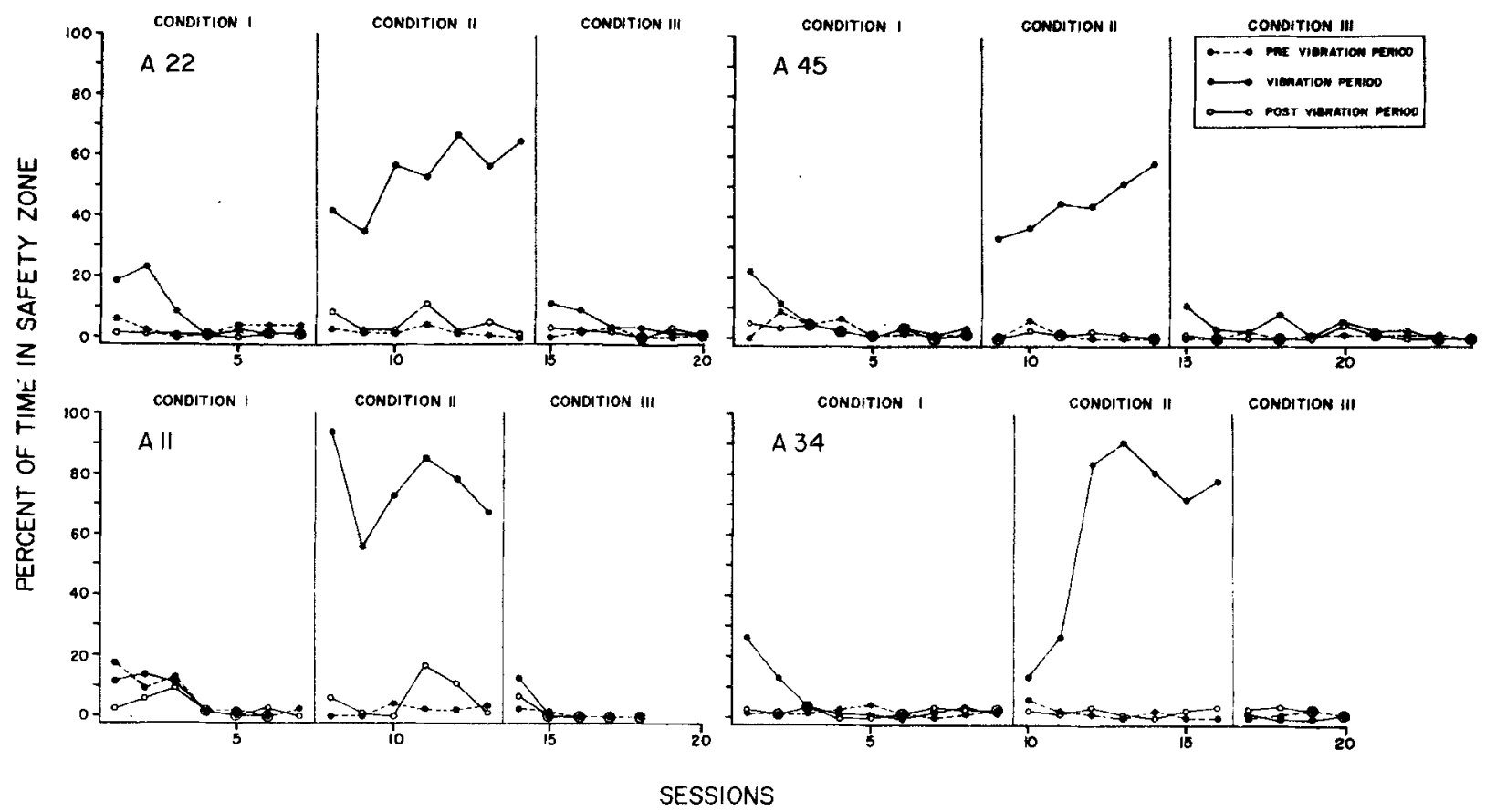

Figure 4. Percentage of time spent in the safety zone for four subjects during the three conditions. The largest amount of time was spent in the safety zone when the escape contingency was introduced in Condition 2.

The experiment consisted of three conditions presented sequentially. In Condition 1 , inescapable vibratory stimulation was presented (i.e., entrance into the safety zone did not turn off vibration). During Condition 2, each response terminated the stimulus for the duration of that response. Condition 3 was identical to Condition 1 (i.e., inescapable vibration). Subjects received exposure to each condition until the total time spent in the safety zone did not differ more than $10 \%$ over four consecutive sessions. Sessions lasting $9 \mathrm{~min}$ were run approximately every $5 \mathrm{~h}$. Sessions consisted of a 3-min experimental period in which responses either terminated the stimulus (Condition 2) or had no effect (Conditions 1 and 3). This period was preceded and followed by $3 \mathrm{~min}$ of no vibration. The data obtained from Conditions 1 and 3 were baseline measures used to assess the possibility that the subject might be attracted to the safety zone solely on the basis of the heat given off by the infrared emitter. If heat attracted the subjects, it was assumed that the ants would spend most of the session in the safety zone. As shown in Figure 4, this clearly was not the case. The only increase in time spent in the safety zone occurred during Condition 2 , when the escape contingency was introduced.

\section{REFERENCES}

Autrum, H. Über genör und erschutterungssinn bie; Locustiden. Zeitschrifi Fuer Vergleichende Physiologie, 1941, 28, 580-637.

Longo. N.. Holland. L. R., \& Bitterman. M. E. The resistive sheet: A gridless and wireless shocking technique. American Journal of Psychology, 1961, 74, 612.618.

Martinsen. D. L.. \& Kimeldorf. D. J. Conditioned spatiai avoidance behavior of ants induced by $\mathrm{X}$-rays. Psychological Record, 1972, 22. 225-232.

(Received for publication May 6, 1977: revision accepted August 9, 1977.) 